\section{Discussion}

Although several predisposing factors have been identified $^{1-3}$ the trigger for febrile convulsion remains elusive. Previous studies have shown slowing of background rhythms during and after pyrexial illnesse ${ }^{3}$ and during artificially induced fever. ${ }^{4}$ The background rhythms in the present study were generally slower than expected for the children's ages but no fluctuation with temperature was detected, suggesting the slowing is caused by an effect of the infection other than fever.

It has been suggested that fever precipitates reflex anoxic seizures that progress to typical febrile convulsions. ${ }^{6}$ None of the present children had asystole, and seizure activity occurred independently of cardiac rhythm. We are unable to exclude asystole as the final precipitating event for clinically observable seizures, but seizure activity in this study could not be attributed to anoxia. Our findings did not help to predict early recurrences of febrile convulsion.
We thank Miss J Gibbs for technical assistance and Miss M Chilcott for secretarial assistance.

\section{References}

${ }^{1}$ Lewis HM, Parry JV, Parry RP, et al. Role of viruses in febrile convulsions. Arch Dis Child 1979;54:869-76.

${ }^{2}$ Wallace SJ. Pyrexial convulsions. In: Rose FC, ed. Paediatric neurology. Oxford: Blackwell, 1979:346-59.

${ }^{3}$ Wallace SJ, Zealley H. Neurological, electroencephalographic and virological findings in febrile children. Arch Dis Child 1970;45:611-23.

${ }^{4}$ Baird HW, Garfunkel JM. EEG changes in children with artificially induced hyperthermia. J Pediatr 1956;48:28-33.

${ }^{5}$ Millichap JG. Studies in febrile seizures. I. Height of body temperature as a measure of the febrile seizure threshold. Pediatrics 1959;23:76-85.

${ }^{6}$ Stephenson JBP. Two types of febrile seizure, anoxic (syncopal) and epileptic mechanisms differentiated by oculocardiac reflex. Br Med J 1978;ii:726-8.

Correspondence to Dr S J Wallace, University Hospital of Wales, Heath Park, Cardiff CF4 4XW.

Received 11 December 1983

\title{
Weight as the best standard for glomerular filtration in the newborn
}

\author{
M G COULTHARD AND E N HEY \\ Department of Child Health, University of Newcastle upon Tyne
}

SUMMARY The relation between surface area and body weight changes dramatically in infancy. In 31 healthy infants of 27 to 40 weeks' gestation, variations in glomerular filtration rate were reduced more than twofold by choosing glomerular filtration rate/kg body weight rather than glomerular filtration rate $/ \mathrm{m}^{2}$. The former provides the most useful and practical index of renal function in the neonate.

Although the use of surface area for standardising glomerular filtration rate minimises age and weight dependent variations in children and adults, this has never been tested in infancy, when surface area:weight changes most dramatically. We have, therefore, tested glomerular filtration rate data from preterm and term babies to find which standard reduces the variation most effectively.

\section{Patients and methods}

Thirty one well babies of 27 to 40 weeks' gestation weighing 0.68 to $3.7 \mathrm{~kg}$ were studied between 2 and 7 days of age. Twenty five $(81 \%)$ of the infants were below the 50th centile for weight and $11(35 \%)$ were below the 10th. Glomerular filtration rate was measured by the 24 hour constant inulin infusion method $^{1}$ on average three times for each baby, and the mean value taken. Surface area was estimated by Boyd's formula ${ }^{2}$ and a weight index was calculated as weight:50th centile weight. The study had the approval of the local ethical committee, and informed parental consent was obtained.

\section{Results}

Glomerular filtration rate values varied more than 10 fold between babies $(0.50$ to $5.71 \mathrm{ml} / \mathrm{min})$, but only fivefold when expressed per unit surface area $\left(4.5\right.$ to $\left.22.6 \mathrm{ml} / \mathrm{min} / \mathrm{m}^{2}\right)$ and less than threefold when expressed per unit body weight $(0.59$ to 1.56 $\mathrm{ml} / \mathrm{min} / \mathrm{kg}$ ). Glomerular filtration rate $/ \mathrm{m}^{2}$ and glomerular filtration rate $/ \mathrm{kg}$ were each positively correlated with weight $(\mathrm{P}<0.001)$, gestational age $(\mathrm{P}<0 \cdot 001)$, and weight index $(\mathrm{P}<0 \cdot 05)$. Multiple 


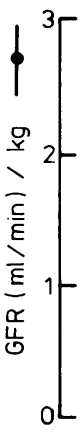
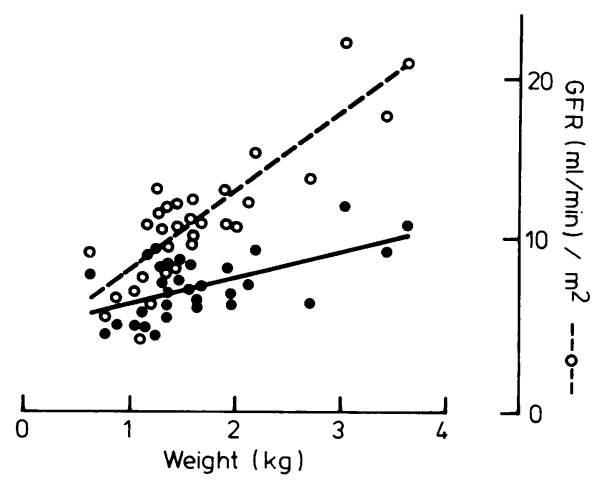

Fig. 1 Regression of glomerular filtration rate $(G F R) / \mathrm{m}^{2}$ and glomerular filtration rate $(G F R) / \mathrm{kg}$ on weight in 31 babies in the first week of life. Each point is the mean value for one baby.

For glomerular filtration rate $/ \mathrm{m}^{2} ; \mathrm{y}=3.67+4.55 \mathrm{x}, \mathrm{r}=0.82, \mathrm{P}<0.001$ For glomerular filtration rate/kg; $y=0.623+0.196 x, r=0.60, P<0.001$

regression analysis, however, showed that when weight was accounted for there was no longer any association with either gestation or weight index ( $P>0.25$ in each case). The slope of the regression line relating glomerular filtration $\mathrm{rate} / \mathrm{m}^{2}$ to body weight is two and a half times steeper than that for glomerular filtration rate/kg $(\mathrm{P}<0 \cdot 05)$ (Fig. 1). Glomerular filtration rate $/ \mathrm{m}^{2}$ therefore shows wider variations between infants of different sizes than glomerular filtration rate $/ \mathrm{kg}$.

\section{Discussion}

The ratio of glomerular filtration rate to surface area hardly changes between age 2 years and adulthood, while surface area:weight falls by about $40 \%$. Surface area:weight ratio alters much more dramatically, however, during infancy (it is about four times higher for a baby of 27 weeks' gestation than for an adult) and falls by one third between 27 weeks' and term (Fig. 2). For a physiological function to vary with surface area, its value per kilogram in early life would have to be large and change very rapidly. To maintain a glomerular filtration rate of $80 \mathrm{ml} / \mathrm{min} /$ $\mathrm{m}^{2}$, a baby of 27 weeks' gestation would need to filter $8 \mathrm{ml} / \mathrm{min} / \mathrm{kg}$, whereas the figure for an adult would be $2 \mathrm{ml} / \mathrm{min} / \mathrm{kg}$.

The metabolic rate determines the need for the excretion of waste products. Basal metabolic rate and glomerular filtration rate correlate in older children and adults in that they each vary closely with surface area. Metabolic rate has been expressed both as metabolic rate $/ \mathrm{m}^{2}$ and metabolic

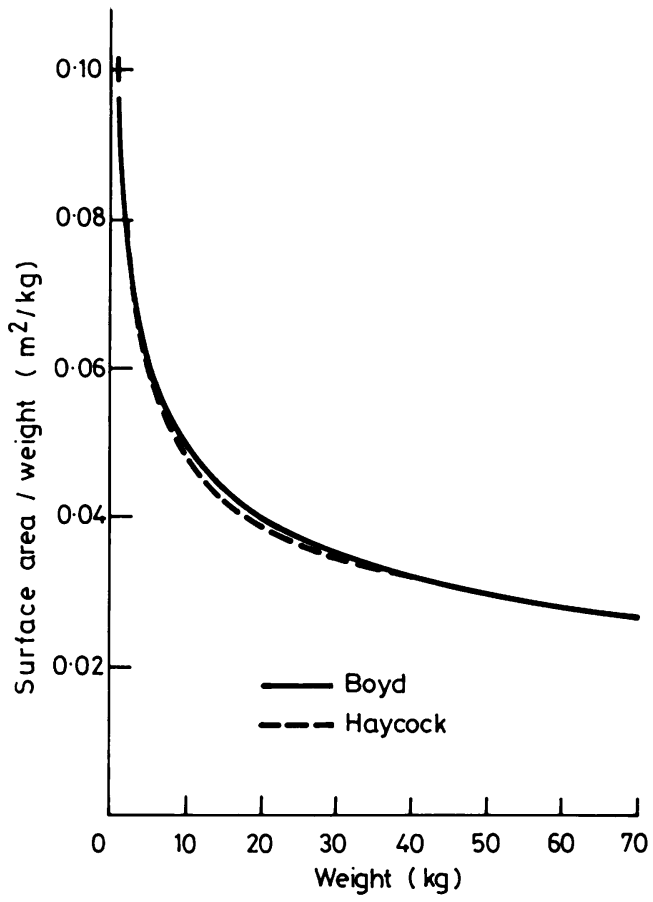

Fig. 2 Relation between surface area to weight ratio $(S A / W)$ and body weight, calculated (a) from Boyd $d^{2}$ and (b) from Haycock et al ${ }^{7}$ using the 50th centile values from national height and weight standards.

rate $/ \mathrm{kg}$ in newborn infants; the advantage of using metabolic rate $/ \mathrm{kg}$ is shown by data previously presented by one of us. ${ }^{3}$ The effects of environmental temperature and postnatal age on metabolic rate were easily recognised because size related variations were eliminated. If the same data are expressed per surface area, the regression of metabolic rate $/ \mathrm{m}^{2}$ on both weight and gestation $(\mathrm{P}<0 \cdot 01)$ almost masks the effects of the other factors. Our finding that glomerular filtration rate is more closely related to weight than surface area in newborns, therefore, fits well with the data on metabolic rate.

The use of surface area to 'correct' neonatal glomerular filtration rate may be more than a mere extrapolation of convention; it may relate to the unifying 'law of surface area'. This century old law has, however, been shown to be invalid, and its use has led to many false conclusions. ${ }^{4}$ Over 30 years ago, McCance and Widdowson ${ }^{5}$ argued that the incorrect selection of surface area as a basis for comparison had delayed the understanding of juvenile renal function, but predicted pessimisti- 
cally that changes in established practice would be opposed.

A major disadvantage of standardising glomerular filtration rate to surface area is that formulas for estimating surface area from weight or weight and length are based on relatively few actual measurements in the smallest weight range and have never been systematically tested in babies of varying body proportions. Practical neonatal management decisions, including those regarding calorie intake, temperature control, and fluid, electrolyte, and drug administration are almost universally made on the basis of body weight, which can be measured directly. Even workers who standardise their glomerular filtration rate results $/ \mathrm{m}^{2}$ generally calculate the doses of their test substances per $\mathrm{kg}$ body weight. For research findings to be usefully assimilated and applied clinically, they should be expressed in the same way as other parameters.

It has been argued that it would be logical to relate glomerular filtration rate to the size of the fluid pool affected by the kidney ${ }^{5}{ }^{6}$ but this has three disadvantages. Firstly, like surface area, fluid volumes would be estimated rather than measured. Secondly, no single fluid space would be appropriate to all aspects of renal function; total body water would be best for urea and water handling, ${ }^{5}$ and extracellular fluid volume for inulin or mannitol clearances. ${ }^{6}$ Thirdly, like surface area:weight, the total body water:weight and extracellular fluid volume:weight ratios fall with increasing postconceptual age, exaggerating the rises in glomerular filtration rate with increasing body size.

We have shown that weight, the only reference standard that can be actually measured and is clinically useful, is the best index for neonatal glomerular filtration rate measurement. To expect a single standard to apply to all patients weighing from 1 to $70 \mathrm{~kg}$ is simplistic, however, and could be misleading. It is better to consider glomerular filtration $\mathrm{rate} / \mathrm{kg}$ as useful in the newborn period and glomerular filtration $\mathrm{rate} / \mathrm{m}^{2}$ as convenient in older children, and not to place physiological importance on either approach.

We thank Mrs Valerie Ruddock for skilled technical assistance and Mrs Marjorie Renwick for secretarial help. This work was supported by Medical Research Council project grant 9979279 .

\section{References}

1 Coulthard MG. Comparison of methods of measuring renal function in pre-term babies using inulin. $J$ Pediatr 1983;102: 923-30.

2 Boyd E. The growth of the surface area of the human body. Minneapolis: University of Minnesota Press, 1935.

${ }^{3}$ Hey EN. The relation between environmental temperature and oxygen consumption in the new-born baby. $J$ Physiol 1969;200:589-603.

${ }^{4}$ Tanner JM. Fallacy of per-weight and per-surface area standards, and their relation to spurious correlation. J Appl Physiol 1949:2:1-15.

5 McCance RA, Widdowson EM. The correct physiological basis on which to compare infant and adult renal function. Lancet 1952;ii:860-2.

' Newman EV, Bordley J, III, Winternitz J. The interrelationships of glomerular filtration rate (Mannitol clearance), extracellular fluid volume, surface area of the body, and plasma concentration of mannitol: definition of extracellular fluid clearance determined by following plasma concentration after single injection of mannitol. Bulletin of the Johns Hopkins Hospital 1944:75:253-68.

7 Haycock GB. Schwartz GJ. Wisotsky DH. Geometric method for measuring body surface area: a height-weight formula validated in infants. children, and adults. $J$ Pediatr 1978:93:62-6

Correspondence to Dr M G Coulthard. Guys Hospital, St Thomas Street, London SE1 9RT.

Received 20 November 1983

\title{
Cushing's syndrome and bronchial carcinoid tumour
}

\author{
P S WARD, M G MOTT, J SMITH, AND M HARTOG \\ Bristol Royal Hospital for Sick Children and Southmead Hospital, Bristol
}

\begin{abstract}
SUMmary Adrenal function test results in a girl with Cushing's syndrome and a bronchial carcinoid tumour suggested pituitary dependent hypercortisolism. Resolution after excision of the tumour indicated that her condition had been caused by ectopic adrenocorticotrophic hormone secretion. Conventional tests of adrenal function may be misleading in cases of adrenocorticotrophic hormone secreting bronchial carcinoid tumours.
\end{abstract}

The aetiology of Cushing's syndrome can usually be determined from the serum adrenocorticotrophic hormone concentration and the response of urinary corticosteroids to high dose dexamethasone and metyrapone. ' In some circumstances, however, these investigations may be misleading. ${ }^{2}$ We report a patient who seemed to have pituitary dependent hypercortisolism but was subsequently shown to have an adrenocorticotrophic hormone secreting bronchial carcinoid tumour. 